\title{
Como Atuam Psicólogos na Educação Pública Paulista? Um Estudo Sobre suas Práticas e Concepções
}

How Do Psychologists In São Paulo State Public Education

Work? A Study About Their Practices And Conceptions

Kátia Yamamoto, Aline de Araújo Leite Santos, Camila Galafassi, Mariana Guimarães Pasqualini \& Marilene Proença Rebello de Souza

\section{Universidade de São Paulo}

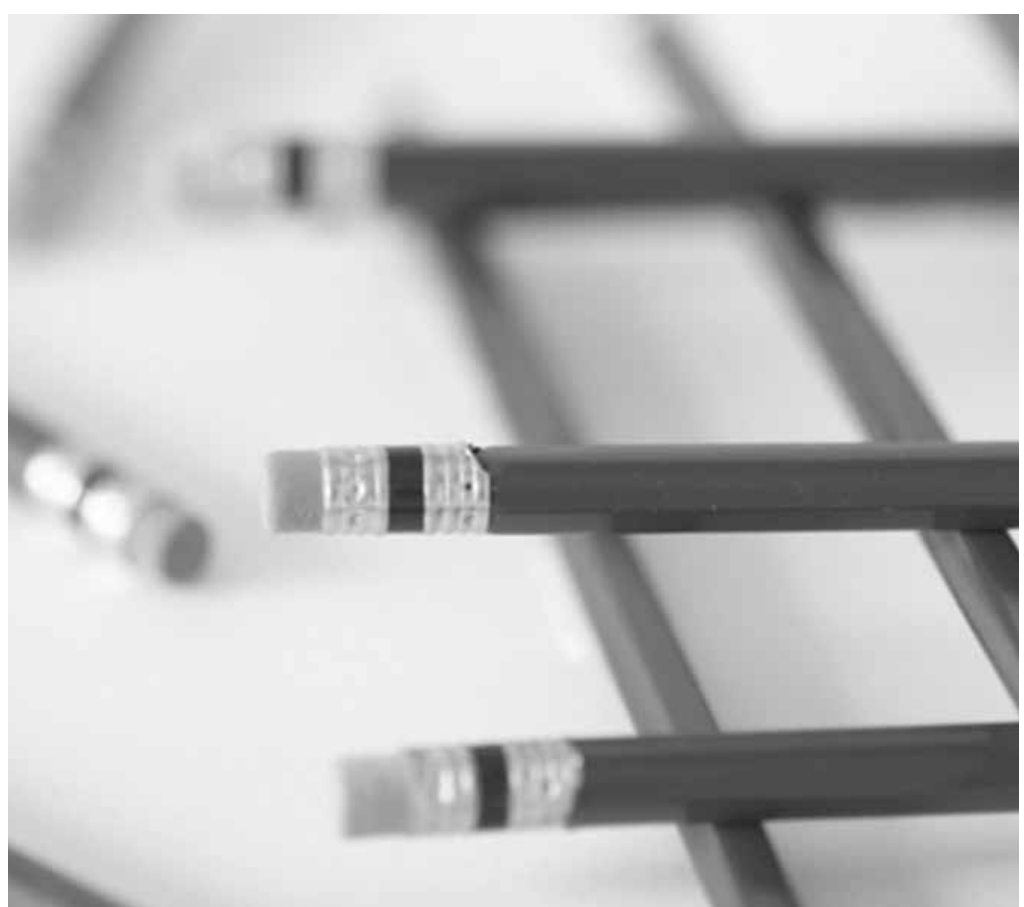


Resumo: Este artigo tem por objetivo analisar de que maneira concepções e práticas desenvolvidas pelos psicólogos da rede pública frente às queixas escolares vêm incorporando discussões recentes, oriundas da Psicologia escolar e educacional, e que destacam a importância das dimensões histórico-culturais na constituição do fenômeno educativo. Serão apresentados dados obtidos por meio de questionários respondidos por 108 psicólogos que atuam em 45 Secretarias de Educação paulistas. As análises realizadas permitem considerar que as práticas e as concepções dos psicólogos mesclam elementos tradicionais de compreensão do fenômeno educativo com visões mais críticas sobre o processo de escolarização. A atuação desses profissionais, dentre outros aspectos, revela elementos que expressam dimensões de sua formação profissional, das políticas públicas municipais, das concepções de educação que cada administração possui, da história de constituição do serviço, da disponibilidade de cada escola e de seus gestores para aceitar um trabalho institucional e do reconhecimento da função de psicólogo escolar.

Palavras-chave: Atuação do psicólogo. Psicologia escolar. Educação. Ensino público.

Abstract: This paper examines how the concepts and practices developed by school psychologists from the public education system have been incorporating recent discussions in the areas of educational and school psychology, highlighting the importance of the historical and cultural dimensions of educational phenomenon. This paper presents the data obtained through a questionnaire answered by 108 psychologists who work at 45 education departments in São Paulo State. The data demonstrate that the practices and concepts merge traditional and innovative elements, suggesting that psychologists are appropriating the discussions in the area, but the request for clinical and individual treatment of children with school difficulties still remains. The performance of these professionals, among other things, is an expression of their training, municipal public policies, conceptions of education of each administration, history of the constitution of the service, availability of each school and its managers to accept an institutional perspective, and recognition of the school psychologist's role.

Keywords: Psychologist performance. School psychology. Education. Public school education.

Resumen: Este artículo tiene como objetivo analizar de qué manera las concepciones y prácticas desarrolladas por los psicólogos de la red pública frente a las quejas escolares vienen incorporando discusiones recientes, oriundas de la Psicología escolar y educacional, y que destacan la importancia de las dimensiones históricas culturales en la constitución del fenómeno educativo. Se presentarán datos obtenidos por medio de cuestionarios respondidos por 108 psicólogos que actúan en 45 Secretarías de Educación paulistas. Los análisis realizados permiten considerar que las prácticas y concepciones de los psicólogos mezclan elementos tradicionales de comprensión del fenómeno educativo con visiones más críticas sobre el proceso de escolarización. La actuación de estos profesionales, entre otros aspectos, revela elementos que expresan dimensiones de su formación profesional, de las políticas públicas municipales, de las concepciones de Educación que cada administración posee, de la historia de constitución del servicio, de la disponibilidad de cada escuela y sus gestores para aceptar un trabajo institucional, del reconocimiento de la función de psicólogo escolar.

Palabras claves: Actuación del psicólogo. Psicología escolar. Educación. Enseñanza pública.

Apoio: $\mathrm{CNPq}$ e FAPESP
No Brasil, a partir da década de 80 , constituíram-se as primeiras críticas ao modelo de atuação profissional do psicólogo escolar, de cunho psicodiagnóstico, psicoterapêutico e reeducativo. Tais críticas se centram no argumento da predominância do referencial positivista de ciência, presente na pesquisa em Psicologia e em Psicologia escolar e educacional, que desconsidera, dentre outros aspectos, os elementos institucionais e políticos na constituição do processo de escolarização (Patto, 1981). As críticas geradas no campo acadêmico sobre o modelo clínico de atuação profissional propiciaram importantes reflexões acerca das práticas a serem desenvolvidas por psicólogos no âmbito da educação e ofereceram importantes subsídios para desvelar os determinantes sociais e históricos que constituíram o (des)encontro entre a Psicologia e a educação (Barbosa, 2012) e para reafirmar a possibilidade da construção de perspectivas mais adequadas no campo da pesquisa e da atuação profissional. Compreender, portanto, a atuação psicológica no campo educacional em uma perspectiva crítica, analisar a queixa apresentada pela escola como expressão das dimensões políticas, sociais, relacionais e institucionais passou a ser objeto de estudo de vários pesquisadores brasileiros (Patto, 2000; 
Podemos

considerar que as críticas centrais

da área de

Psicologia escolar e educacional apresentaram-

se, nos anos

90, em dois grandes eixos: na necessidade de superar a noção unilateral de adaptação da criança ao sistema escolar e na atuação do psicólogo como profissional independente do corpo

administrativo da escola (Maluf, 1994).

1 É o caso do Município de São Paulo, na gestão de Guiomar Namo de Mello à frente da Secretaria Municipal de Educação, extinguindo o então

Departamento

de Assistência ao Escolar, fundado em 1956.

2 Não foram encontrados psicólogos que

atuam na Secretaria

de Educação do

Estado de São Paulo.
Machado, 1994, 1996, 2008; Souza, 2007, 2008, 2010; Souza \& Silva, 2009; Souza \& Rocha, 2011; Bock, 2002; Antunes, 2008; Meira, 2012; Meira \& Tanamachi, 2008).

Podemos considerar que as críticas centrais da área de Psicologia escolar e educacional apresentaram-se, nos anos 90, em dois grandes eixos: na necessidade de superar a noção unilateral de adaptação da criança ao sistema escolar e na atuação do psicólogo como profissional independente do corpo administrativo da escola (Maluf, 1994). Assim sendo, uma atuação do psicólogo escolar centrada nessa perspectiva precisaria, dentre outros aspectos, considerar: a) a produção da queixa como expressão dos processos escolares vividos por todos os atores que os compõem, b) a construção de referenciais interpretativos em Psicologia que tenham como princípio a construção de uma história não documentada, composta por diferentes versões (criança, pais, professores, psicólogo) a respeito da criança e de sua relação com a escolarização e c) a apropriação de referenciais pedagógicos histórico-críticos que expressem as finalidades da educação (Souza \& Checchia, 2008).

Por sua vez, a discussão sobre a autonomia do trabalho do psicólogo frente à escola e as críticas à atuação profissional ao longo dos anos 80 influenciaram uma série de práticas políticas na rede pública de educação, que tiveram, basicamente, duas tendências: a) retirada total do psicólogo escolar do sistema educacional ${ }^{1}$ e b) transferência de psicólogos da escola e formação de equipes de trabalho nas Secretarias municipais e estaduais.

Mas, apesar das importantes discussões trazidas pela Psicologia escolar a respeito da escolarização, pouco se sabe, do ponto de vista da pesquisa em Psicologia escolar e educacional, como trabalham esses profissionais após esses 30 anos de discussões no interior da Psicologia escolar, tampouco se sabe que práticas desenvolvem, que desafios enfrentam em suas condições de trabalho, como entendem o processo educacional e quais representações possuem das crianças, das famílias e dos professores com quem trabalham. Em que aspectos as discussões produzidas no âmbito acadêmico têm repercutido nas práticas levadas a efeito pelos profissionais de Psicologia no campo da educação básica? Que políticas públicas têm sido geradas no campo da atuação do psicólogo frente à demanda escolar? Essas ações estão vinculadas às discussões sobre o compromisso social do psicólogo com uma prática emancipatória frente à demanda escolar?

Tais questionamentos mobilizaram o desenvolvimento da pesquisa intitulada: Atuação do psicólogo na rede pública de educação frente à demanda escolar: concepções, práticas e inovações, estudo que envolveu grupos de pesquisadores em sete Estados brasileiros: Rondônia, Acre, Bahia, Minas Gerais, São Paulo, Paraná e Santa Catarina. Para tanto, foram realizadas três etapas de levantamento e de análise de dados, entre os anos 2006 a 2010, que consistiram em: a) mapeamento dos serviços oferecidos pelas Secretarias estaduais e municipais de educação desses sete Estados nos quais atuem psicólogos e levantamento das práticas profissionais realizadas por meio de questionário e entrevistas, b) compilação das publicações científicas da área de Psicologia escolar e educacional, identificando como se apresentam as principais tendências quanto à atuação do psicólogo no campo da educação e c) levantamento e análise da atuação profissional de psicólogos na área da educação.

O presente artigo apresentará um recorte desta pesquisa no que tange à análise do material constituído por meio dos questionários respondidos por psicólogos que atuam em Secretarias Municipais² de Educação 
do Estado de São Paulo. A aplicação do questionário teve como propósito permitir a caracterização geral dos profissionais e das equipes que atuam nas Secretarias, assim como possibilitar o reconhecimento das modalidades de atuação profissional e a compreensão das concepções que respaldam suas práticas, buscando identificar indícios que apontassem o exercício de práticas inovadoras e que expressassem discussões teórico-metodológicas do campo da Psicologia escolar e educacional que denominamos crítica.

\section{Método}

Para obter informações a respeito da equipe de psicólogos e de seus integrantes como profissionais que atuam nas Secretarias Municipais de Educação, utilizou-se o questionário visando a oferecer uma caracterização inicial das modalidades de atuação dos psicólogos e das concepções que respaldavam suas práticas. O questionário era de preenchimento individual, e as perguntas giravam em torno do tempo de trabalho do profissional na equipe, seu cargo, formação e, de modo amplo, sua filiação teórica e modalidades de atuação de que se utiliza para responder às demandas escolares. Esse questionário estruturou-se nos seguintes eixos: dados gerais de identificação, formação, níveis de ensino em que atua, público-alvo da intervenção, modalidades de atuação, projetos desenvolvidos, fundamentação teórica e contribuições da Psicologia para a educação.

O questionário permitiu obter informações importantes a respeito da atuação dos psicólogos da rede pública de educação e possibilitou identificar aqueles que, por expressarem concepções ou descreverem práticas inseridas nas finalidades da educação em uma perspectiva crítica, foram convidados a participar da segunda etapa da pesquisa, em que pudemos conhecer mais detalhadamente o trabalho realizado por profissionais e equipes. As respostas obtidas pelo questionário foram analisadas tanto por instrumentos de caráter quantitativo, em relação à distribuição da amostra e à frequência dos dados, como também por leituras de caráter qualitativo, com categorizações das respostas por similitudes dos conteúdos, principalmente em relação às questões abertas.

A análise estatística utilizou o programa Statistical Package for Social Sciences (SPSS), verificando de que maneira as informações obtidas a partir dos diferentes eixos do questionário se associam, o que permitiu a constituição de perfis dos psicólogos que atuam na rede pública de educação no Estado de São Paulo. Dos 164 questionários enviados, 108 foram respondidos, correspondendo a profissionais que atuam em 45 Municípios do Estado de São Paulo. Tal análise propiciou avaliar a associação entre pares de variáveis por meio do Teste Qui-quadrado, para verificar quais delas eram significativas. Todos os pares possíveis de variáveis foram testados. A constatação de associações significativas entre variáveis demonstra a existência de um padrão na distribuição dos dados, determinado por dependência entre essas variáveis. A partir das associações significativas entre pares de variáveis, foi utilizada a análise de correspondência (ANACOR) para verificar as associações significativas entre duas ou mais variáveis. Essa análise gera um mapa multidimensional que permite entender como as variáveis se associam, podendo-se criar perfis, ou seja, a partir dos resultados obtidos com essa análise, pode-se dizer, por exemplo, se há associação entre a formação em determinado tipo de instituição de ensino superior ou em determinado tipo de curso realizado após a graduação, a modalidade de atuação adotada e o público-alvo da intervenção, se estão associados o tempo de formação e as concepções a respeito do papel do psicólogo na educação ou, ainda, como se 
associam as influências teóricas à modalidade de atuação e aos níveis de ensino em que a intervenção é realizada.

\section{Resultados e discussão}

Para compor a amostra da pesquisa, foram selecionados 133 Municípios (20,6\% do total de Municípios paulistas), escolhidos de forma a abranger diferentes regiões do Estado. Em 61 deles (45,9\% dos contatados), existiam psicólogos no quadro de funcionários das Secretarias de Educação, 58 (43,6\%) Municípios não contavam com psicólogos e 14 (10,5\%) não forneceram a informação sobre o número de psicólogos ou não foi possível concluir o contato. Assim, foram contatados 220 profissionais, dos quais $108(49,1 \%)$ participaram da pesquisa respondendo ao questionário. Do conjunto dos participantes, 96,4\% são mulheres, com média de idade de 40 anos $(89,6 \%$ na faixa entre 26 e 55 anos).

Quanto às Secretarias Municipais de Educação nas quais trabalham os psicólogos, foi possível perceber que há uma grande diversidade referente ao número de profissionais que compõem os serviços: há tanto Municípios que possuem equipes de psicólogos quanto aqueles que possuem apenas um psicólogo, que atende sozinho a demanda da cidade como um todo. Um dado que chamou a atenção é que, na região da grande São Paulo, houve maior frequência de Municípios que possuem equipes de psicólogos: das 11 cidades da Grande São Paulo que possuem psicólogos na Secretaria de Educação nessa região, 8 são compostas por equipes.

No questionário da presente pesquisa, havia uma questão relativa ao cargo e à função na Secretaria Municipal de Educação, na qual o profissional poderia nomear livremente sua situação nesses dois itens. Tal diferenciação se mostrou pertinente, pois muitos psicólogos apontaram diferenças entre o cargo de contratação e a função que efetivamente exercem. No quesito cargo, que reúne as respostas psicólogo (53) e psicólogo escolar (29), obtivemos o valor de $76 \%$ da amostra. No que se refere à função, enquanto $49 \%$ dos psicólogos afirmaram atuar como tal, 32\% especificaram sua função como psicólogo escolar, educacional ou da educação. Contudo, é importante apontar que, em 44,5\% da amostra, há desvio de função, ou seja, há uma parcela significativa de profissionais contratados para outros cargos (professor, supervisor, coordenador, psicopedagogo), mas que atuam como psicólogos. Para compreender esse fato, é preciso problematizar as questões que o atravessam, como a não legitimação do lugar do psicólogo na educação, evidenciada pela falta de uma legislação específica que regulamente esse cargo (Souza \& Rocha, 2011). Por outro lado, dentre os que ocupam a função de psicólogo, é grande o número dos que se denominam trabalhadores específicos da educação, o que revela um importante processo de construção de identidade profissional própria, em contraste com psicólogos que atuam na saúde, por exemplo, que são maioria.

A média de tempo de trabalho na Secretaria é de 8,7 anos. Em geral, os profissionais foram contratados no final da década de 90 , e ocupam o cargo de psicólogos na educação há cerca de duas gestões municipais.

\section{Formação}

Quanto à formação dos psicólogos, foi possível identificar que $66 \%$ concluíram sua formação inicial em Psicologia há mais de nove anos, sendo 14,7 anos a média de tempo de formação dessa amostra. Isso demonstra que esses profissionais, para estarem por dentro das discussões recentes da área, tiveram que procurar cursos, eventos e literatura e investir em cursos complementares após concluir sua graduação. Constatou-se que $27 \%$ dos participantes se formaram há 5 anos ou menos. É interessante 
É importante destacar que São Paulo é o Estado que agrega o maior número de instituições de ensino superior, com 537 das 2.252 IES espalhadas nacionalmente, o que corresponde a $24 \%$ desse total (IBGE, 2010). observar que, do total da amostra, 30,5\% disseram ter se formado há mais de 20 anos, quando as discussões e as reflexões em Psicologia escolar e educacional ainda estavam no início. Observou-se também uma prevalência de instituições de ensino superior particulares, que foram citadas por $78,7 \%$ dos participantes, enquanto as estaduais foram citadas em $12,1 \%$ das respostas, as federais, $2,8 \%$ e as municipais, a minoria, com $1,8 \%$. É importante destacar que São Paulo é o Estado que agrega o maior número de instituições de ensino superior, com 537 das 2.252 IES espalhadas nacionalmente, o que corresponde a $24 \%$ desse total (IBGE, 2010). Quanto aos cursos realizados após a graduação, foi pedido ao participante que assinalasse no questionário entre as opções doutorado, mestrado, especialização, aprimoramento, atualização e/ou outros. Observou-se que 93\% dos psicólogos pesquisados fizeram algum tipo de curso de pós-graduação, o que denota que têm uma preocupação em continuar sua formação, e isso pode interferir significativamente em sua atuação. Esse número foi ainda maior entre os psicólogos que atuam na região da Grande São Paulo, na qual apenas um dos profissionais que responderam ao questionário não realizou nenhum tipo de pós-graduação $(1,8 \%)$. Os cursos de especialização ou de aprimoramento foram indicados por $72 \%$ dos psicólogos, enquanto os stricto sensu foram citados por $10 \%$.

Quanto ao tema desses cursos, a presença na amostra de psicólogos que de alguma forma fizeram cursos relacionados à educação inclusiva é expressiva, sendo responsável por $22 \%$ do total. Notou-se que tal temática era mais presente na formação de profissionais que trabalhavam em equipes, principalmente em equipes da Grande São Paulo. O investimento em cursos nessa seara provavelmente se deve em grande parte à política de educação inclusiva. Um pequeno número de participantes mencionou cursos de pós-graduação relacionados à Psicologia escolar e educacional, cerca de 9\%. Um dado interessante é que esses $9 \%$ eram formados majoritariamente por psicólogos que atuam na Grande São Paulo, verificando-se uma grande influência da Universidade de São Paulo (USP) no relato dos cursos realizados após a graduação. Outra área que merece destaque é a psicopedagogia. Cursos de pósgraduação nessa área foram citados por 15,7\% dos participantes, principalmente por aqueles que atuam na Região Sudeste/litoral, na qual $50 \%$ dos psicólogos mencionaram essa opção.

\section{Concepções teórico-práticas da atuação do psicólogo}

A respeito das referências teórico-metodológicas com as quais os psicólogos têm embasado sua atuação, houve uma grande diversidade tanto de autores quanto de obras citadas pelos participantes. O autor mais mencionado pelo conjunto de psicólogos que respondeu o questionário foi Lev S. Vigotski, citado por $46 \%$ dos participantes. Essa grande quantidade de citações pode significar um avanço no entendimento da escolarização em uma perspectiva histórico-cultural, que considera os aspectos sociais e culturais para o desenvolvimento humano, porém, a existência de divergências teóricas na compreensão das concepções desse autor não permite afirmar que a atuação psicológica baseada em sua obra siga essa perspectiva. Outros autores da Psicologia do desenvolvimento também se destacam, como Jean Piaget e Henri Wallon.

Do ponto de vista da Psicologia escolar e educacional brasileira, foram citados autores que contribuíram com discussões na área em uma perspectiva crítica, tais como Maria Helena Souza Patto, Adriana Marcondes Machado, Maria Cristina Machado Kupfer e Marilene Proença. Compareceram também com frequência autores clássicos da Psicologia clínica, principalmente os de base psicanalítica, como Sigmund Freud, Donald Winnicott e Jacques Lacan. 
Nota-se a referência a autores da educação, como Paulo Freire, Miguel Arroyo, Elvira de Souza Lima e Celso Vasconcellos, o que demonstra uma aproximação com as concepções e temáticas da área de atuação. A referência expressiva a Maria Teresa Egler Mantoan corrobora a forte atuação dos psicólogos no âmbito da educação inclusiva, e a presença de José Bleger indica uma preocupação com o enfoque institucional no trabalho junto à educação.

Houve predominância de participantes (53\%) que citaram tanto autores ligados à educação e à Psicologia escolar e educacional quanto autores da área clínica.

A partir da análise das respostas referentes ao tema da contribuição do psicólogo para a educação, identificamos três grupos de tendências de atuação:

a) tendência clínica: inclui respostas que apresentam uma atuação profissional individualizada, baseada em diagnóstico e tratamento dos problemas de aprendizagem. O papel do psicólogo é avaliar alunos, visando a identificar que problemas em seu desenvolvimento estão comprometendo o desempenho escolar, detectando e corrigindo os desvios que se apresentam quanto ao padrão de normalidade. O psicólogo comparece como profissional que atua de forma paralela à educação, em caráter complementar, não realizando intervenções diretas nos processos escolares. A contribuição que esse profissional pode dar à educação é realizar um trabalho clínico, em muitos casos utilizando a avaliação psicológica como instrumental, seguida de atendimento clínico, orientação e/ou encaminhamentos. O enfoque está centrado no aluno, incluindo professores e familiares apenas para dar devolutivas e orientações sobre como proceder para auxiliar na adaptação do aluno, e pode estender-se a estes também em caráter de avaliação de condutas e de suporte psicológico clínico;

b) tendência institucional: reúne respostas referentes a formas de intervenção em que a atuação tem como foco a instituição educativa como um todo, incluindo os diversos atores do contexto escolar. O psicólogo comparece como profissional que problematiza o não aprender como um fenômeno contextual e não individual. Para tanto, atua no processo de escolarização, levando em consideração todos os envolvidos nesse processo, e também no âmbito institucional, configurado pelas relações de poder e atravessado pelas políticas públicas. São apontadas como funções de seu trabalho contribuir para que haja melhor comunicação entre os diferentes setores da escola, atuando na mediação de conflitos, e proporcionar espaços de reflexão visando a promover o rompimento de relações cristalizadas, a fim de minimizar as ações discriminatórias e excludentes. A organização do trabalho é feita a partir da elaboração, junto à equipe escolar, de projetos de intervenção que levem em consideração as demandas e as necessidades de cada instituição. Foram relatados trabalhos em equipes multidisciplinares e parcerias com outras Secretarias municipais. Teve destaque a atuação do psicólogo no campo da educação inclusiva, que apresenta como contribuições orientar professores sobre como trabalhar com os alunos com deficiência e orientar direção, pais e alunos para auxiliar no processo de inclusão, mediando as relações entre eles;

c) tendência clínica e institucional: abarca respostas em que compareceram características de ambas as tendências, situando-se em uma posição intermediária entre a tendência clínica e a institucional. $\mathrm{O}$ foco de intervenção encontra-se no estudante, a partir de uma compreensão do não aprender relacionado ao desenvolvimento infantil e às diferenças individuais, porém, é considerado importante abranger também 
outros componentes da escola, como pais, professores e equipe gestora. Embora o foco ainda esteja no indivíduo, na detecção de problemas individuais do aluno e em sua adaptação ao sistema escolar, comparecem também elementos voltados para o trabalho com o aspecto coletivo, como: dar suporte aos professores e à equipe gestora, intervir de forma a melhorar os relacionamentos entre professor-aluno e atuar proporcionando reflexões e desmistificando preconceitos, entre outros exemplos.

\section{Atuação profissional}

Na questão sobre os níveis de ensino em que os psicólogos atuam, os respondentes podiam assinalar uma ou mais destas alternativas: 1) educação infantil, 2) ensino fundamental, 3) ensino médio, 4) educação de jovens e adultos ou 5) outros. Ao analisar as respostas, conclui-se que em apenas $25 \%$ dos questionários havia somente uma das respostas assinalada: em $15 \%$, os psicólogos atuavam exclusivamente no ensino fundamental, em $8 \%$, na educação infantil, e, em $2 \%$, na educação de jovens e adultos. Na grande maioria dos casos, os psicólogos assinalaram mais de um item, indicando uma atuação mais ampla. Do total das respostas, $34 \%$ dos questionários tiveram os itens ensino fundamental e educação infantil assinalados, confirmando a importância desses níveis de ensino. Em segundo lugar, em 18\%, os psicólogos assinalaram educação infantil, ensino fundamental e EJA, e em $6 \%$ foram marcadas todas as opções.

Embora educação inclusiva/especial não se configure como um nível de ensino, muitos participantes (28\%), ao escolherem a opção outros, relataram trabalhar com essa modalidade. Optou-se então por inserir essa resposta em uma categoria específica, por entendermos que tal trabalho traz especificidades importantes e que, muitas vezes, engloba todos os níveis de ensino ${ }^{3}$.
Na questão sobre o público-alvo do trabalho, os itens que poderiam ser assinalados eram: 1) alunos, 2) professores, 3) pais de alunos, 4) funcionários e 5) outros. Havia a possibilidade de assinalar mais de uma opção. Na Tabela 1, temos as frequências relativas a essa questão:

Tabela 1. Porcentagem de psicólogos participantes em São Paulo em relação ao público alvo com o qual atuam $(n=108)$

\begin{tabular}{ll}
\hline Público-alvo & $\begin{array}{c}\text { Porcentagem de psicólogos } \\
(\%)\end{array}$ \\
\hline Professores & $89 \%$ \\
Alunos & $83 \%$ \\
Pais & $79 \%$ \\
Funcionários & $40 \%$ \\
\hline
\end{tabular}

Ao contabilizar a frequência de cada resposta, sem ainda levar em consideração de que forma elas se agruparam no mesmo questionário, percebeu-se alta frequência em todas elas, indicando que de fato a maioria dos participantes assinalou várias opções. Ao analisar de que forma essas respostas se agruparam nos questionários, algumas combinações merecem destaque, como se pode ler na Tabela 2:

Tabela 2. Porcentagem dos psicólogos participantes em São Paulo em relação ao agrupamento das respostas que citaram o público alvo com o qual atuam $(n=108)$

\begin{tabular}{lc}
$\begin{array}{l}\text { Agrupamento de } \\
\text { respostas relacionadas } \\
\text { ao público-alvo }\end{array}$ & $\begin{array}{c}\text { Porcentagem } \\
\text { de psicólogos } \\
(\%)\end{array}$ \\
\hline Alunos, pais e professores & $34 \%$ \\
Alunos, professores, pais & \\
e funcionários (todas as opções) & $40 \%$ \\
Somente professores & $9 \%$ \\
Alunos e pais & $5 \%$ \\
Somente alunos & $3 \%$ \\
Outros & $9 \%$ \\
\hline
\end{tabular}


Chamou a atenção também o fato de 34 \% dos psicólogos terem preenchido a opção outro nessa questão, sendo mais frequentes as respostas que citavam como público-alvo os diretores, os coordenadores, a equipe gestora, os programas sociais e a comunidade em geral. Esses resultados podem indicar que os profissionais atuam de forma a abranger todos os envolvidos no processo de escolarização e/ou pode ainda refletir que os psicólogos podem ora trabalhar com um público-alvo, ora com outro, atuando, entretanto, com todos os públicos, mas de modo separado.

Na questão sobre modalidades de atuação, os itens que poderiam ser assinalados eram: 1) avaliação psicológica, 2) atendimento clínico, 3) formação de professores, 4) assessoria às escolas e 5) outro. Assim como nas duas questões anteriores, poderia ser assinalada mais de uma opção. Notou-se que a grande maioria dos profissionais assinalou duas ou mais opções dentre as quatro descritas, demonstrando realizar um trabalho que envolve diversas modalidades de atuação, o que pode ser visto na Tabela 3 :

Tabela 3. Porcentagem dos psicólogos participantes em São Paulo em relação à modalidade de atuação em que atuam $(n=108)$

\begin{tabular}{lc}
$\begin{array}{l}\text { Modalidades de } \\
\text { Atuação }\end{array}$ & $\begin{array}{c}\text { Porcentagem } \\
\text { de psicólogos } \\
(\%)\end{array}$ \\
\hline Formação de professores & $69,4 \%$ \\
Assessoria às escolas & $63,5 \%$ \\
Avaliação psicológica & $58,3 \%$ \\
Atendimento clínico & $40,2 \%$ \\
\hline
\end{tabular}

Como podemos observar na Tabela 4, abaixo, a combinação mais frequente das modalidades foi entre formação de professores e assessoria às escolas, indicando uma tendência de intervenção institucional, embora tenha sido descrita certa multiplicidade de atividades dentro dessas duas modalidades, que tanto apresentaram como foco da atuação a instituição escolar quanto trouxeram encaminhamentos individuais para os problemas escolares.

Tabela 4. Porcentagem dos psicólogos participantes em São Paulo em relação ao agrupamento das respostas que se referem à modalidade de atuação com a qual atuam $(\mathrm{n}=108)$

$\begin{array}{lc}\text { Agrupamento de } & \text { Porcentagem } \\ \text { respostas relacionadas } & \text { de psicólogos } \\ \text { à modalidade de atuação } & (\%)\end{array}$

Formação de professores

e assessoria às escolas $19 \%$

Avaliação psicológica, atendimento clínico, formação de professores e assessoria às escolas $15 \%$ Avaliação psicológica, formação de professores e assessoria às escolas $13 \%$ Avaliação psicológica e atendimento clínico $9 \%$

Destacam-se também os questionários que apresentavam como resposta apenas a formação de professores (7\%) e a opção outros, assinalada por $52 \%$ dos psicólogos, cuja descrição do trabalho apresentou grande diversidade de atividades realizadas, como atendimento familiar, processos seletivos, discussão de casos com coordenadores e professores, participação em conselhos municipais, organização de eventos, formação de monitores e elaboração de relatórios, entre outras.

Para analisar as combinações entre as opções desse item do questionário, foram elaboradas três categorias de respostas, a partir dos itens assinalados pelos psicólogos: 1) atuação clínica, que abarca respostas que incluem apenas as modalidades de avaliação psicológica e atendimento clínico, 2) atuação 
institucional, indicando respostas que reúnem apenas as opções formação de professores e assessoria às escolas, e 3) atuação clínica e institucional, referente às respostas que mesclam opções das duas categorias anteriores. Com essa divisão, observou-se que houve predominância da terceira categoria, a modalidade clínica e institucional, com 55\% dos participantes. A atuação institucional ficou com $30 \%$ das respostas, e a clínica, com $15 \%$.

Foi realizada análise estatística utilizando a análise de correspondência (ANACOR), visando a compreender de que maneira as respostas dadas aos diferentes itens do questionário se associavam, o que possibilitou vislumbrar perfis de atuação do psicólogo paulista no campo da educação.

Buscando a formação de perfis do psicólogo paulista que atua na rede pública de educação, foi verificada a associação entre os itens modalidade de atuação e público-alvo $\left(c^{2}=51,531, g l=8\right.$, $p=0,000$ ). Constatou-se que psicólogos com uma atuação institucional têm como público-alvo predominantemente o corpo docente e os funcionários. Profissionais que apresentaram uma atuação voltada para a clínica têm como público-alvo o aluno e a família. A atuação clínica e institucional está associada às categorias todos e pais, alunos e professores, indicando a realização de trabalho com público-alvo bastante amplo. A Figura 1 ilustra essa distribuição dos três perfis:

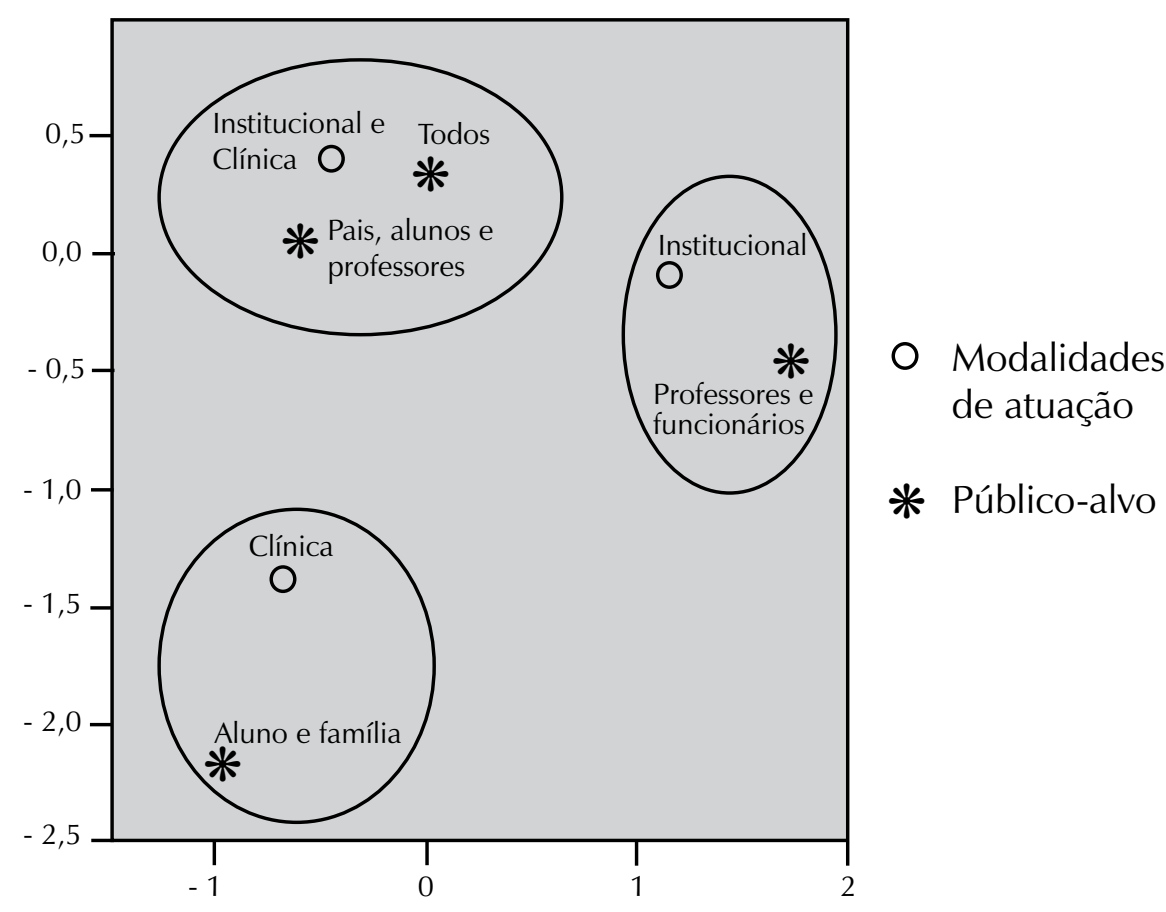

Figura1. Mapa perceptual com a associação significativa entre as variáveis Modalidades de atuação e público-alvo $\left(c^{2}=51,531, g l=8, p=0,00\right)$.

A análise estatística deste estudo vai ao encontro do que vem sendo apontado pelos teóricos da Psicologia escolar e educacional em uma perspectiva crítica, segundo a qual o trabalho do psicólogo escolar em um modelo tradicional tem como principal objetivo atender os alunos e seus pais e realizar avaliações psicológicas em uma modalidade clínica e individualizante. 
Por outro lado, os psicólogos escolares que fazem a crítica a esse tipo de atuação, em sua maioria, trabalham em uma perspectiva institucional, buscando abarcar diferentes públicos-alvo.

\section{Projetos desenvolvidos}

Dentre os 108 psicólogos, 96 citaram projetos desenvolvidos na área da educação (89\%), apresentados a seguir de acordo com os temas a que se referem.

O tema mais recorrente nos projetos descritos foi educação inclusiva. Cabe observar que, em vários Municípios contatados, foram encontrados centros de atendimento voltados exclusivamente para a atuação psicológica nesse âmbito. Foram citados projetos em que os profissionais trabalhavam de forma a garantir a inclusão dos alunos com deficiências na rede regular de ensino, projetos relacionados a acompanhamento, atendimento e triagem de alunos, atendimento multidisciplinar e orientação a professores e à família e projetos voltados especificamente para pessoas com deficiência auditiva.

O segundo tipo de projeto mais encontrado diz respeito ao trabalho com alunos. Os projetos, apresentados a seguir em ordem decrescente, abordavam temas voltados para o público infanto-juvenil, como sexualidade, drogas, mercado de trabalho e orientação profissional, atendimento clínico e avaliação psicológica, dificuldades de aprendizagem, atendimento psicopedagógico e atendimento inter/ multidisciplinar. Em apenas um dos projetos ligados à dificuldade de aprendizagem foi explicitada uma preocupação em não apenas atender os alunos com dificuldade, mas sim, em abordar, dentro da escola, as questões que podem levar ao fracasso escolar. Além disso, foram relatados projetos que visavam a procurar formas de tornar o ambiente escolar mais atrativo e prazeroso.
A terceira categoria com maior número de projetos descritos refere-se ao trabalho com educadores. A grande maioria dos psicólogos relatou atuar com formação de professores, abordando formação, capacitação e/ou treinamento dos professores/educadores, e apenas um psicólogo disse realizar atendimento clínico a educadores. Outros projetos referiram-se a encontros de professores/educadores e a grupo de estudos com docentes.

Outro tipo de projeto bastante recorrente envolveu o trabalho com famílias, no formato de encontros com grupos de pais e/ou mães e realização de atendimentos a pais. Grande parte desses projetos tinha como propósito orientá-los a agirem de forma a acarretar mudanças no comportamento escolar dos filhos. Alguns projetos procuravam realizar simultaneamente um trabalho com alunos, família e professores, voltando-se para o relacionamento entre escola e família, trabalhando temas como questões ligadas à ética e aos valores, saúde, acompanhamento escolar e o brincar.

Alguns projetos são direcionados para o trabalho com funcionários, envolvendo formação acerca da educação inclusiva, capacitação do núcleo operacional da escola, grupos com funcionários com temáticas não explicitadas e curso de gestão para diretores. Esses projetos demonstram uma tentativa de abranger todos os atores institucionais como participantes ativos do ambiente escolar.

Parte dos projetos era voltada especificamente para o trabalho com creches, envolvendo formação de educadores de creches e abordando diferentes temáticas, como, por exemplo, a relação entre creche e família e sexualidade infantil. Foram relatados também projetos de assessoria a unidades de ensino que apresentaram uma abordagem ligada a questões institucionais, buscando implicar todos os atores no processo de 
escolarização, por exemplo, atuando junto à escola na construção de seu projeto político-pedagógico. Alguns projetos apresentaram como foco a queixa escolar, em um enfoque institucional, procurando entender as inúmeras relações presentes no ambiente escolar e superar práticas educacionais cristalizadas, desvencilhando-se de um olhar individualizante sobre o fracasso escolar. Houve ainda projetos caracterizados como indefinidos, pois pouca ou nenhuma informação foi fornecida sobre seu públicoalvo e seus objetivos.

Diante do que pôde ser observado a respeito dos projetos citados pelos participantes, notase uma grande diversidade no público-alvo, nos propósitos e na forma de trabalho de cada profissional. Há uma ampla variedade de concepções que embasam esses projetos, desde práticas que se assemelham a um modelo tradicional até aquelas que se aproximam de uma abordagem crítica em Psicologia escolar e educacional.

\section{Considerações finais}

Nesta pesquisa, buscou-se realizar um mapeamento dos profissionais e dos serviços oferecidos pelos psicólogos nas Secretarias Municipais de Educação, identificando as concepções teórico-metodológicas e as modalidades de trabalho na educação, com destaque para as práticas que apresentaram indícios de uma atuação em uma perspectiva crítica.

Analisando as práticas e as concepções apresentadas pelos participantes desta pesquisa em São Paulo, verificou-se uma apropriação diversa de teorias e modalidades de atuação do psicólogo na educação, que pode ser sintetizada em três categorias: a) clínica, b) clínica e institucional e c) institucional. De maneira geral, observouse maior concentração nas duas últimas categorias (b e c).
A atuação desses profissionais, dentre outros aspectos, expressa a sua formação, as políticas públicas municipais, as concepções de educação que cada administração possui, a história de constituição do serviço, a disponibilidade de cada escola e de seus gestores para aceitar um trabalho institucional e o reconhecimento da função de psicólogo escolar, que é diferenciada daquela do psicólogo que trabalha na saúde.

Embora esses profissionais procurem realizar uma prática alicerçada em ações institucionais, a demanda escolar continua fortemente marcada pela solicitação do atendimento individual e clínico, o que gera tensão entre o serviço oferecido e as expectativas da escola. Essa tensão intensifica-se a partir de um retorno da visão medicalizante, que atribui à criança as causas de sua não aprendizagem. Embora consistentemente criticada por autores tanto da Psicologia escolar como da Medicina, da Linguística e da educação, essa visão tem influenciado políticas públicas na área e exigido dos psicólogos maior empenho em explicitar aos professores novas possibilidades de compreensão e de atendimento da queixa escolar. Nesse contexto, torna-se imprescindível a formação contínua e de qualidade desses profissionais.

A quase totalidade dos participantes mencionou ter realizado alguma modalidade de curso de atualização, pós-graduação (lato sensu e stricto sensu) ou supervisão, o que nos leva a crer que há uma forte tendência dos psicólogos em dar continuidade ao seu processo formativo. Mas também foi possível verificar que grande parte dessa formação ainda se insere na dimensão clínica ou de áreas afins, o que instaura a necessidade de se constituir, de fato, uma formação complementar na área específica de atuação, a Psicologia escolar e educacional.

Além da importância da formação, mostrouse também essencial a influência de fatores 
ligados à estrutura dos serviços e das Secretarias na atuação do psicólogo escolar, havendo alguns limites de atuação que são colocados por esses fatores, por isso, o trabalho de construção de uma Psicologia escolar e educacional em uma perspectiva crítica envolve uma constante luta política pela formação de qualidade, pelo reconhecimento do psicólogo escolar como um profissional da educação, distinto do profissional da saúde, e pelo fim da medicalização excessiva dos alunos, dentre muitos outros temas que interessam diretamente aos profissionais da área. Essa perspectiva deve ultrapassar os limites da Academia e alcançar principalmente o campo das políticas públicas, pois é a partir destas que as mudanças podem efetivar-se e as inovações proporcionadas na formação podem de fato ser colocadas em prática.

\section{Kátia Yamamoto}

Mestre em Psicologia Escolar e do Desenvolvimento Humano pela Universidade de São Paulo, São Paulo - SP - Brasil.

E-mail: katinhay@gmail.com

\section{Aline de Araújo Leite Santos}

Graduada em Psicologia pela Universidade de São Paulo, São Paulo - SP - Brasil.

E-mail: aline.araujo.santos@usp.br

\section{Camila Galafassi}

Graduada em Psicologia pela Universidade de São Paulo, São Paulo - SP - Brasil.

E-mail: camila.galafassi@usp.br

\section{Mariana Guimarães Pasqualini}

Graduada em Psicologia pela Universidade de São Paulo, São Paulo - SP - Brasil.

E-mail: marianagp02@gmail.com

Marilene Proença Rebello de Souza

Doutora em Psicologia Escolar pela Universidade de São Paulo e docente da Universidade de São Paulo, São Paulo - SP - Brasil .

E-mail: marileneproenca@hotmail.com

\section{Endereço para envio de correspondência:}

Rua Monte Caseros, 126, ap. 76A, Vila Gomes. CEP: 05590-130. São Paulo, SP.

Recebido 27/02/2013, 1a Reformulação 28/08/2013, Aprovado 29/08/2013. 


\section{Referências}

Antunes, M. A. M. (2008). Psicologia e educação no Brasil: um olhar histórico-crítico. In M. E. M. Meira \& M. A. M. Antunes (Orgs.), Psicologia escolar: teorias críticas (2a ed., pp. 139168). São Paulo: Casa do Psicólogo

Barbosa, D. R. (2012). Contribuições para a construção da historiografia da psicologia educacional e escolar no Brasil. Psicologia: Ciência e Profissão, 32(Spe.), 104-123. doi: http:// dx.doi.org/10.1590/S1414-98932012000500008

Bock, A. M. B. A. (2002). Psicologia sócio-histórica: uma perspectiva crítica em psicologia. In A. M. B. Bock, M. G. M. Gonçalves \& O. Furtado. Psicologia sócio-histórica:uma perspectiva crítica em psicologia. São Paulo: Cortez.

Instituto Brasileiro de Geografia e Estatística. (IBGE). (2012). Censo Demográfico 2010. Resultados Gerais da Amostra. Rio de Janeiro: Autor.

Machado, A. M. (1994). Crianças de classe especial: efeitos do encontro entre saúde e educação. São Paulo: Casa do Psicólogo.

Machado, A. M. (1996). Crianças de classe especial. São Paulo: Casa do Psicólogo.

Machado, A. M. (2008). Os psicólogos trabalhando com a escola: intervenção a serviço do quê? In M. E. M. Meira \& M. A. A. Antunes (Orgs.), Psicologia escolar: práticas críticas (pp. 63-86). São Paulo: Casa do Psicólogo.

Maluf, M. R. (1994). Formação e atuação do psicólogo na educação: dinâmica de transformação. In Conselho Federal de Psicologia. Psicólogo brasileiro: práticas emergentes e desafios para a formação (pp. 157-200). São Paulo: Casa do Psicólogo.

Meira, M. E. M. (2012). Contribuições da psicologia históricocultural para a psicologia da educação. In I. A. T. V. Filhão \& R. F. Ponce (Orgs.), Psicologia \& educação: perspectivas críticas para a ação psicopedagógica (pp. 47-79). Birigui, SP: Boreal Editora.

Meira, M. E. M., \& Tanamachi, E. R. (2008). A atuação do psicólogo como expressão do pensamento crítico em psicologia e educação. In M. E. M. Meira \& M. A. M. Antunes (Orgs.), Psicologia escolar: práticas críticas (pp. 11-62). São Paulo: Casa do Psicólogo.
Patto, M. H. S. (1981). (Org.), Introdução à psicologia escolar. São Paulo: T. A. Queiroz.

Patto, M. H. S. (2000). A produção do fracasso escolar: histórias de submissão e rebeldia (2a. ed.) São Paulo: Casa do Psicólogo.

Souza, M. P. R. (2007). Reflexões a respeito da atuação do psicólogo no campo da psicologia escolar/educacional em uma perspectiva crítica. In H. R. Campos (Org.), Formação em psicologia escolar: realidades e perspectivas (pp. 149-162). Campinas, SP: Alínea.

Souza, M. P. R. (2008). Problemas de aprendizagem ou problemas na escolarização? Repensando o cotidiano escolar à luz da perspectiva histórico-crítica em psicologia. In D. Trento, M. Oliveira \& T. Rego (Orgs.), Psicologia, educação e as temáticas da vida contemporânea (3a ed., pp. 177-196). São Paulo: Editora Moderna.

Souza, M. P. R. (2010). Psicologia escolar e políticas públicas em educação: desafios contemporâneos. Em Aberto, 23, 129-149.

Souza, M. P. R., Bastos, A. V., \& Barbosa, D. R. (2011). Formação básica e profissional do psicólogo: análise do desempenho dos estudantes no ENADE-2006. Avaliação Psicológica, 10(3), 295-312.

Souza, M. P. R., \& Checchia, A. K. A. (2008). Queixa escolar e atuação profissional: apontamentos para a formação de psicólogos. In M. E. M. Meira \& M. Antunes. Psicologia escolar: teorias críticas (2a ed., pp. 105-138). São Paulo: Casa do Psicólogo.

Souza, M. P. R., \& Rocha, M. L. (2011). Políticas educacionais: legislação, formação profissional e participação democrática. In M. G. D. Facci, M. M. Meira \& S. Tuleski (Orgs.), A exclusão dos incluídos. Uma crítica da psicologia da educação à patologização e medicalização dos processos educativos (pp. 345-370). Maringá, PR: UEM.

Souza, M. P. R., \& Silva, S. M. C. (2009). A atuação do psicólogo na rede pública de educação frente à demanda escolar: concepções, práticas e inovações. In C. M. Marinho-Araujo (Org.), Psicologia escolar. Novos cenários e contextos de pesquisa, formação e prática (pp. 75-106). Campinas, SP: Alinea. 